\title{
Fall in the incidence of Crohn's disease
}

\author{
J KYLE AND G STARK
}

From the Gastroenterology Research Unit, Royal Infirmary, Aberdeen

SUMMARY Chronic transmural inflammatory bowel disease was first described in Scotland by Dalziel in 1913. A study has been made of new cases arising in the Aberdeen area during the 21 years, 1955-75, and is continuing. The number of new cases developing each year rose from $1 \cdot 2$ per 100000 population at the beginning of the study to a peak of 4.5 in 1969. Thereafter it gradually declined, the mean incidence during the three year period $1973-75$ being only 2.6 per 100000 . The decline has affected both males and females. It has been more marked in city dwellers than in the rural population. The former preponderance of city cases has almost disappeared. Disease apparently confined to the small intestine is less common than in 1955 , when it constituted $77 \%$ of the cases recorded. Today the large intestine or combined forms make up $75 \%$ of the new cases which are seen. There is no obvious explanation for the fall in incidence or change of site.

The first complete description of chronic transmural inflammatory bowel disease was given in two lectures delivered in Glasgow and Brighton by Sir T Kennedy Dalziel in 1913.1 ${ }^{2}$ During the years 1901-12 he had operated on nine patients suffering from what he termed 'chronic interstitial enteritis' at the Western Infirmary, Glasgow. Three of his patients had the disease confined to the large intestine, while in two patients both small and large intestines were extensively involved. The outbreak of the first world war and his death at the comparatively early age of 63 years probably prevented Dalziel from continuing his study of the disease which he had discovered. Interest in the condition was reawakened by Crohn and his colleagues nearly two decades later. ${ }^{3}$

More than 50 years elapsed before another series of patients was reported from Scotland. ${ }^{4}$ In a further study of patients in north-east Scotland it was observed that the incidence was rising steadily up to the end of $1968 .{ }^{5} \mathrm{~A}$ similar observation was made in the Uppsala district of Sweden. ${ }^{6}$ A large influx of patients suffering from Crohn's disease into the Aberdeen hospitals was anticipated during the 1970s. It did not materialise.

\section{Methods}

DIAGNOSTIC CRITERIA

Only those patients in whom the diagnosis was beyond reasonable doubt were accepted. Patients had

Received for publication 6 November 1979 to meet at least two out of the following four diagnostic criteria: (1) clinical features-diarrhoea, abdominal colic, weight loss; (2) macroscopic appearances-at operation or necropsy; (3) microscopic features-on biopsy or respected specimens; (4) radiological features characteristic of Crohn's disease. Observation over a number of years was of assistance in doubtful cases.

\section{GEOGRAPHICAL LIMITS}

The Aberdeen teaching hospitals serve the medical needs of a clearly defined, relatively closed community of 441200 people (1971 Census) ${ }^{7}$. Females constituted $52.2 \%$ of the population at risk. The population had decreased by $1500(0.3 \%)$ since the 1961 Census. $^{8}$ Only those patients who had lived for at least two years in the City of Aberdeen (population 182100 ) and in the surrounding counties of Kincardineshire, Aberdeenshire, Banffshire, and Morayshire (populations 259 100) were included.

Tourists, foreign fishermen, members of the Armed Services, and patients suffering from acute, self-limiting ileitis were excluded.

\section{ASCERTAINMENT}

All the inpatient records for north-east Scotland have been available through the Central Records Department, Aberdeen, since 1955, and the computer print-out and retrieval services of the Department have proved highly reliable. Reports of all barium enemas and barium meals performed after 1965 
have been filed in this Unit, and these have been searched. In addition, all morbid anatomy in the Region is undertaken by the University Department of Pathology, whose records have been scrutinised.

\section{Results}

The new study of results was conducted during 1978 . Every patient had been admitted to hospital at some time during the course of his disease, and the year of onset of symptoms had been noted. As the mean interval between onset and diagnosis in the present series is 17 months the epidemiological data is confined to those patients whose disease began before 1976. Because of the relatively small numbers of patients, for statistical analyses patients have been aggregated into three, six or nine year groups.

NEW CASES

There were 272 new cases during the 21 years 1955-75 inclusive in the indigenous population (Table 1); 97 were males and 175 females $(64 \%)$. The annual incidence per 100000 rose from 1.2 in the first three year period to a peak of 4.5 in 1967-69, and has since declined to $2 \cdot 6$. Provisional figures for 1976 and 1977 suggest a further decrease to $1 \cdot 7$.

The difference in the attack rates in males and in females is consistent and real. The rise in incidence and subsequent fall is highly significant, the level of

Table 1 New cases of Crohn's disease in north-east Scotland, 1955-75

\begin{tabular}{lccll}
\hline Year of onset & Males & Females & Totals & $\begin{array}{l}\text { Incidence per } \\
100000 \text { patients }\end{array}$ \\
\hline $1955-57$ & 7 & 9 & 16 & $1 \cdot 2$ \\
$1958-60$ & 11 & 14 & 25 & $1 \cdot 9$ \\
$1961-63$ & 12 & 25 & 37 & $2 \cdot 8$ \\
$1964-66$ & 14 & 30 & 44 & $3 \cdot 3$ \\
$1967-69$ & 20 & 39 & 59 & $4 \cdot 5$ \\
$1970-72$ & 25 & 32 & 57 & $4 \cdot 3$ \\
$1973-75$ & 8 & 26 & 34 & $2 \cdot 6$ \\
\hline
\end{tabular}

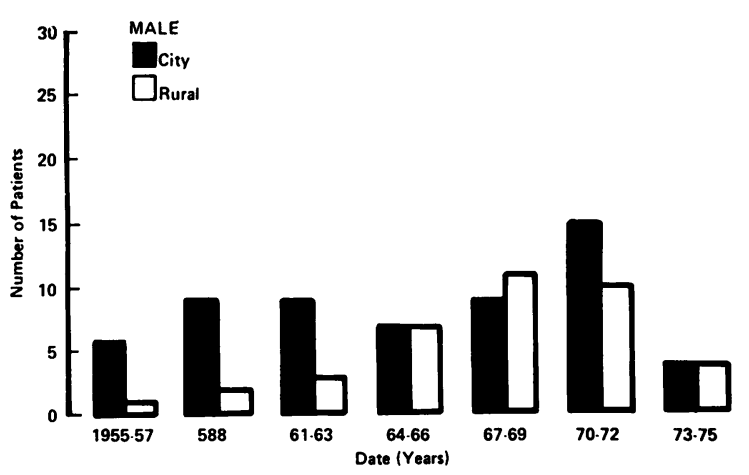

significance being greater for females $\left(x^{2}=25.9\right.$; $\mathrm{DF}=6)$ than for males $\left(x^{2}=18 \cdot 4 ; \mathrm{DF}=6\right)$. The suggestion of a slightly later peak in male subjects is not significant $\left(x^{2}=5 \cdot 6 ; \mathrm{DF}=6\right)$.

\section{PLACE OF RESIDENCE}

The numbers of male and of female patients from the city and from the rural areas are shown in Table 2 , along with the rates in the respective sections of the population. Allowing for possible city/rural differences, the expected numbers in the two contrasting areas can be calculated for males and for females (Table 3). The sex difference is significant at the $0 \cdot 1 \%$ level $\left(x^{2}=15 \cdot 4 ; D F=1\right)$. In the earlier years there had been a marked male predominance in the number of new city patients compared with those coming from the country areas (Figure), but this has

Table 2 Place of residence: numbers of cases and rates in city and in rural areas (rates per 100000 per year)

\begin{tabular}{|c|c|c|c|c|c|c|}
\hline & \multicolumn{2}{|c|}{ Male } & \multicolumn{2}{|c|}{ Female } & \multicolumn{2}{|c|}{ Both sexes } \\
\hline & No. & Rate & No. & Rate & No. & Rate \\
\hline $\begin{array}{l}\text { City } \\
\text { Rural } \\
\text { City + rural }\end{array}$ & $\begin{array}{l}59 \\
38 \\
97\end{array}$ & $\begin{array}{l}3 \cdot 5 \\
1 \cdot 5 \\
2 \cdot 3\end{array}$ & $\begin{array}{r}91 \\
84 \\
175\end{array}$ & $\begin{array}{l}4 \cdot 7 \\
3 \cdot 2 \\
3 \cdot 8\end{array}$ & $\begin{array}{l}150 \\
122 \\
272\end{array}$ & $\begin{array}{l}4 \cdot 1 \\
2 \cdot 4 \\
3 \cdot 1\end{array}$ \\
\hline
\end{tabular}

Table 3 Place of residence: numbers of cases observed and expected for males and for females

\begin{tabular}{lll} 
& Observed & Expected \\
\hline City & & \\
$\quad$ Male & 59 & $69 \cdot 8$ \\
Female & 91 & $80 \cdot 2$ \\
Rural & & \\
$\quad$ Male & 38 & $59 \cdot 5$ \\
Female & 84 & $62 \cdot 5$ \\
Combined city + Rural & \\
Male & 97 & $129 \cdot 3$ \\
Female & 175 & $142 \cdot 7$ \\
\hline
\end{tabular}

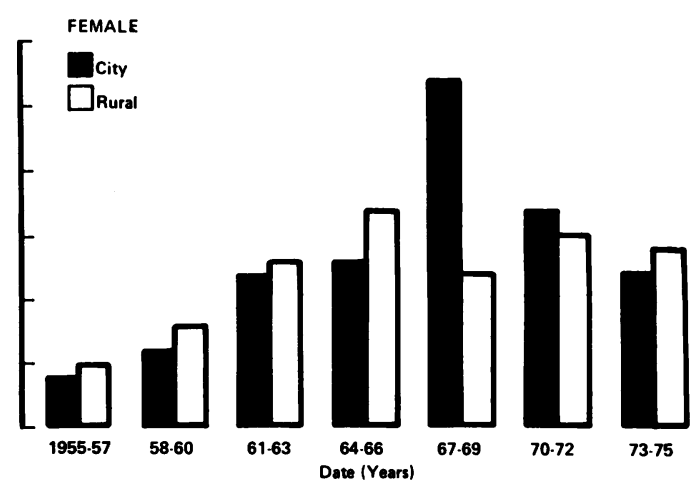

Figure Numbers of male and female patients and their place of residence for seven three-year periods, $1955-75$. 
diminished recently. The change among females has been more striking, with a marked decline in the number of new female patients appearing within the city (Figure).

\section{SITE OF DISEASE}

Three groups based on gross, macroscopic appearances were distinguished for assessing alterations in the site of disease: (1) involvement apparently confined to the large intestine, including rectum; (2) small intestine only affected; (3) both small and large intestine involved, many examples being terminal ileum plus adjacent caecum and ascending colon, but some showing very widespread disease. The cases were aggregated into one nine year and two six year periods in order to calculate the expected numbers in each group and to compare them with those actually observed (Table 4). There has been a steady increase in large intestine only cases, with a gradual decline in the proportion of those strictly limited to the small intestine. Combined forms occupy an intermediate position. When standardised for sex and city/rural differences the gradual change in disease site is significant $\left(\varkappa^{2}=25 \cdot 18 ; \mathrm{DF}=4\right.$, significant at $0 \cdot 1 \%$ level).

\section{Discussion}

The criteria for acceptance into the series have remained unchanged throughout the 21 year period, and one observer has scrutinised all the records, and interviewed over $90 \%$ of the patients. Time of onset has been adhered to in this study, as the onset of symptoms is of more interest from the aetiological point of view than is the date of diagnosis. In an earlier report on the Aberdeen series ${ }^{9}$ the mean interval between onset and diagnosis was 19 months, while the median (or commonest) interval was seven months. In the present extended series these intervals have decreased to 17 months and three months respectively and $90 \%$ of all cases are diagnosed in less than two years.

One of the yardsticks for determining whether or not an observed change in incidence is genuine is to ascertain what has happened to the incidence of comparable diseases. Ulcerative colitis is the condition most closely allied to and most likely to be confused with Crohn's disease. Because of the lack of an Outpatient Diagnostic Index before 1967, the behaviour of ulcerative colitis in north-east Scotland is known with certainty only for the 10 years 1967-76. During this time the annual incidence has remained remarkably constant at 10 to 12 new cases per year. This steady incidence of the principal competing diagnosis, along with the consistent pattern of the changes in males and females, strongly suggests that the rise and subsequent fall in the incidence of Crohn's disease is real, but it remains unexplained. The fall in the number of new cases has been progressive over a period of seven years, and possibly for the last 10 years. It seems unlikely that it could be accounted for by random variation. Within the city of Cardiff the incidence is still rising.$^{10}$ Having first been recognised in Scotland by Dalziel the disease now erroneously called after Crohn is showing the first evidence of a decline in its incidence within the same country. Unfortunately, there is a gap in our knowledge about its behaviour, covering a period of more than half a century but there were peaks in 1901-12 (Glasgow) and 1967-69 (Aberdeen).

In Sweden some evidence supporting the Aberdeen observation has recently emerged. The survey made by Heller ${ }^{11}$ in Stockholm county shows that the incidence of new cases has remained constant during the 1970s, while in Malmo the graph of new cases by year of onset showed a fall in numbers between 1969 and 1973..$^{2}$

Since the 1971 Census, $^{7}$ approximately 14000 people have moved into north-east Scotland as a result of the discovery of oil in the North Sea and the advent of oil-related industries. Most of these newcomers are in the third and fourth decades of life, when inflammatory bowel disease is most likely to appear. In spite of their arrival the disease is less common than it was in 1969.

Crohn's disease may involve any part of the alimentary tract from mouth to anus and seemingly normal parts of the intestines may be actually or

Table 4 Changes in site with time (standardised for sex and city/rural differences)

\begin{tabular}{|c|c|c|c|c|c|c|c|}
\hline \multirow[t]{2}{*}{ Years } & \multicolumn{2}{|l|}{ LI only } & \multicolumn{2}{|l|}{ SI only } & \multicolumn{2}{|l|}{$\begin{array}{l}\text { Combined } \\
L I+S I\end{array}$} & \multirow[t]{2}{*}{ Total } \\
\hline & Observed & Expected & Observed & Expected & Observed & Expected & \\
\hline $\begin{array}{l}1955-63 \\
1964-69 \\
1970-75 \\
\text { All years }\end{array}$ & $\begin{array}{r}3 \\
32 \\
33 \\
68\end{array}$ & $\begin{array}{l}18 \cdot 5 \\
26 \cdot 7 \\
22 \cdot 8\end{array}$ & $\begin{array}{r}39 \\
42 \\
32 \\
113\end{array}$ & $\begin{array}{l}33.0 \\
42.4 \\
37 \cdot 5\end{array}$ & $\begin{array}{l}36 \\
29 \\
26 \\
91\end{array}$ & $\begin{array}{l}26.5 \\
33.9 \\
30.6\end{array}$ & $\begin{array}{r}78 \\
103 \\
91 \\
272\end{array}$ \\
\hline
\end{tabular}


potentially involved. The grouping of cases by macroscopic appearances into large intestinal, small intestinal, and combined forms is somewhat arbitrary, but the principal site of disease has got implications for management, and changes in site over a period of time may indicate that the disease process has altered.

Involvement of the large intestine by chronic transmural inflammation has been recognised with increasing frequency since Lockhart-Mummery and Morson ${ }^{13}$ focused attention on it. There is no obvious explanation for the caudal migration of the lesions noted in the present series. All colectomy specimens from patients originally diagnosed as ulcerative colitis have been re-examined. No evidence has been forthcoming to suggest that cases were misdiagnosed by the pathologists before 1967. The isolated and eminently resectable lesion in the distal ileum is now decidedly less common than formerly. Today the distribution of the chronic inflammatory lesions closely resembles that observed by Dalziel in Glasgow three-quarters of a century ago.

We are grateful to Professor D Kerridge, Department of Statistics, and Professor M Gaskin, Department of Political Economy, University of Aberdeen, for their advice, to Dr T Sinclair for data on ulcerative colitis, and to Mrs $\mathbf{J}$ Amonoo for secretarial assistance.

\section{References}

${ }^{1}$ Dalziel TK. Chronic interstitial enteritis. $\mathrm{Br}$ Med $\mathrm{J}$ 1913; 2: 1068-70.

${ }^{2}$ Dalziel TK. Practical points in abdominal surgery being the 'James Watson Lectures', 1913. Pt III. Glasgow Med J 1914; 82: 338-49 (see 341-6).

${ }^{3}$ Crohn BB, Ginzburg L, Oppenheimer GD. Regional ileitis, a pathologic and clinical entity. JAMA 1932; 99: 1323-9.

${ }^{4} \mathrm{Kyle} \mathrm{J}$, Blair DW. Epidemiology of regional enteritis in north-east Scotland. Br J Surg 1965; 52: 215-7.

${ }^{5} \mathrm{Kyle} \mathbf{J}$. An epidemiological study of Crohn's disease in north-east Scotland. Gastroenterology 1971; 61 : 826-33.

${ }^{6}$ Bergman L, Krause U. The incidence of Crohn's disease in Central Sweden. Scand J Gastroenterol 1975; 10: 725-9.

${ }^{7}$ General Register Office, Scotland 1973. Census 1971, 1 Edinburgh, HMSO.

${ }^{8}$ General Register Office, Scotland 1964. Census 1961, 1 Edinburgh, HMSO.

${ }^{9}$ Kyle J. The early diagnosis of chronic Crohn's disease. Scot Med J 1971 ; 16: 197-201.

${ }^{10}$ Mayberry JF, Rhodes J, Hughes LE. Incidence of Crohn's disease in Cardiff between 1934 and 1977. Gut 1979; 20: 602-8.

${ }^{11}$ Heller G. Crohn's disease in Stockholm county. Acta Chir Scand 1979; suppl. 490.

${ }^{12}$ Brahme F, Lindström C, Wenckert A. Crohn's disease in a defined population. Gastroenterology 1975; 69: $342-51$.

${ }^{13}$ Lockhart-Mummery HE, Morson BC. Crohn's disease (regional enteritis) of the large intestine and its distinction from ulcerative colitis. Gut 1960; 1: 87-105. 